\title{
Anti-inflammatory potential of root and stem extracts of Sesbania sesban
}

Baljinder Singh ${ }^{1,2 *}$, Rajiv Sharma ${ }^{3}$, A.N. Kalia ${ }^{4}$

${ }^{1}$ Lala Lajpat Rai College of Pharmacy, Moga - 142001, Punjab, India.

2I. K. G. Punjab Technical University, Kapurthala - 144603, Punjab, India.

${ }^{3}$ Sri Sai college of Pharmacy, Manawala, Amritsar - 143115, Punjab, India.

${ }^{4}$ Sri Sai college of Pharmacy, Badhani, Pathankot - 145001, Punjab, India.

Received: 10/24/2017; Accepted: 10/28/2017

\begin{abstract}
Successive extracts of root and stem of Sesbania sesban were investigated for in-vitro and in-vivo antiinflammatory potential employing human red blood cell membrane stabilization and rats paw edema methods respectively. Currently much interest is being paid in the search of medicinal plants with potent anti-inflammatory activity which may lead to the discovery of new therapeutic entity. The plant based agents are not only used to suppress the inflammation but also used in different disease conditions where the inflammation responses are amplifying the disease process. The potency of the successive extracts of root and stem of Sesbania sesban were compared with standard diclofenac sodium $(10 \mathrm{mg} / \mathrm{kg} / \mathrm{b} . \mathrm{w}$.). The $\mathrm{n}$-butanol, aqueous and ethyl acetate extracts showed the most significant $(\mathrm{p}<0.01)$ whereas chloroform and total alkaloidal extracts showed modereate antiinflammatory effects on membrane stabilizing action on human red blood cell membrane and inhibition of rats paw edema methods.
\end{abstract}

Keywords: Sesbania sesban, anti-inflammatory, human red blood cell, stabilization method

\section{Introduction}

Inflammation is a self-defense response against tissue injury and it involves a complex group of enzyme activation, fluid extravasations, mediator release, cell migration, tissue breakdown and repair which are aimed at host defense and usually activated in most disease condition (Kumar et al., 2011). Role of inappropriate inflammation is becoming accepted in many diseases that affect man, including cardiovascular diseases, inflammatory and autoimmune disorders, neurodegenerative conditions, infection and cancer. Edema formation, leukocyte infiltration and granuloma formation are main manifestations of inflammation (Kumar et al., 2012). Edema formation in the paw is the result of a synergism between various inflammatory mediators that increase vascular permeability or the mediators that increase blood flow. Carrageenan-induced paw edema is widely used for determining the biphasic phase of inflammation. Histamine, 5-hydroxytryptamine and bradykinin are the first detectable mediators in the early phase of carrageenan-induced inflammation (Ramachandran et al., 2011), whereas prostaglandins are detectable in the late phase of inflammation (Sakat et al., 2010). The present research aims to investigate in-vitro and in-vivo anti-inflammatory activities of root and stem extracts of Sesbania sesban. It is found throughout the plains of India and commonly called as Jayanti. Preliminary phytochemical screening of successive different extracts of root and stems of $S$. sesban revealed the presence of several phytochemical compounds such as triterpenoids, carbohydrates, vitamins, amino acids, proteins, tannins, saponins glycosides and steroids. Traditionally the plant is used in the treatment of inflammatory rheumatic conditions, diarrhea, in excessive menstrual flow, to reduce enlargement of spleen and in skin diseases (Kumar et al., 2014).

\section{Material and Methods}

\section{Plant Material}

The dried plant materials root and stem of Sesbania sesban were collected from S V University, Tirupati, Andhra Pradesh and botanical authentication certificate has been obtained from Dr. K. Madhava Chetty, S V University, Tirupati, Andhra Pradesh. The collected plant materials coarsely powdered. The coarse powder was subjected to successively extracted using chloroform, n- butanol, ethyl acetate, methanol and water as solvents individually.

\section{Animals}

Wistar albino rats, weighing 180-200 g, were obtained from the animal house of the Department of Pharmacology, ISF College of Pharmacy, Moga (Punjab) India under the IAEC approval no. CPCSEA/IAEC/N18/P329. Acute toxicity study was carried out as per standards guidelines. Stem and root extracts of Sesbania sesban were found safe up to a dose level of $4000 \mathrm{mg} / \mathrm{kg} / \mathrm{b} . \mathrm{w}$. The extracts of 100,200 and $300 \mathrm{mg} / \mathrm{kg} / \mathrm{b} . \mathrm{w}$. were used as

\section{${ }^{*}$ Corresponding Author:}

Mr. Baljinder singh

Lala Lajpat Rai College of Pharmacy,

Moga-142001, Punjab, India.

E-mail: bajwabalijinder1@gmail.com

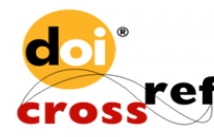


moderate doses for the study. Carrageenan (1\% $\mathrm{w} / \mathrm{w})$ was administered and inflammation was induced in rat paw.

\section{In-vitro anti-inflammatory activity}

The human red blood cell (HRBC) membrane stabilization method (Kumar et al., 2011). The blood was collected from healthy human volunteer who had not taken any NSAIDS for 2 weeks prior to the experiment and mixed with equal volume of Alsever solution ( $2 \%$ dextrose, $0.8 \%$ sodium citrate, $0.5 \%$ citric acid and $0.42 \% \mathrm{NaCl}$ ) and centrifuged at 3,000 rpm. The packed cells were washed with isosaline and a 10\% suspension was made. The concentrations of different successive extracts were prepared (100 and $200 \mu \mathrm{g} / \mathrm{ml})$ using distilled water and to each concentration $1 \mathrm{ml}$ of phosphate buffer, $2 \mathrm{ml}$ hyposaline and $0.5 \mathrm{ml}$ of HRBC suspension were added. It was incubated at $37^{\circ} \mathrm{C}$ for $30 \mathrm{~min}$ and centrifuged at $3,000 \mathrm{rpm}$ for $20 \mathrm{~min}$. and the hemoglobin content of the supernatant solution was estimated spectrophotometrically at $560 \mathrm{~nm}$. Diclofenac $(10 \mu \mathrm{g} / \mathrm{ml})$ was used as reference standard and a control was prepared by omitting the extracts. The percentage of HRBC membrane stabilization or protection was calculated by using the following Formula (Vadivu and Lakshmi, 2008).

$$
\% \text { Protection }=100-\frac{\text { Optical density of drug treated sample }}{\text { Optical density of control }} \times 100
$$

\section{In-vivo anti-inflammatory activity}

The in-vivo anti-Inflammatory activity of stem and root extracts were evaluated using the carrangeenaninduced rat paw edema method (Gandhisan et al., 2008). The rats were divided into eighteen groups $(\mathrm{n}=6)$. Acute inflammation was produced in all groups except normal control by sub plantar administration of of $1 \% \mathrm{w} / \mathrm{w}$ Carrageenan (CAR) in normal saline to the right paw of each rat. Group I normal control (NC) was treated with $0.5 \%$ CMC (5 $\mathrm{mL} / \mathrm{kg} /$ p.o.), Group II was treated with $1 \% \mathrm{w} / \mathrm{w}$ Carrageenan $(5 \mathrm{~mL} / \mathrm{kg} /$ i.p.), Group III-V treated with chloroform extract $\left(\mathrm{CHCl}_{3}\right)$ at the dose of 100 , 200 and $300 \mathrm{mg} / \mathrm{kg} /$ p.o. respectively, Group VIVIII treated with ethyl acetate (EA) extract at the dose of 100, 200 and $300 \mathrm{mg} / \mathrm{kg} /$ p.o. respectively, Group IX and XI treated with n-butanol (nB) extract of $S$. sesban at the dose of 100, 200 and 300 $\mathrm{mg} / \mathrm{kg} /$ p.o., Group XII-XIV treated with aqueous
(Aq) extract at the dose of 100, 200 and 300 $\mathrm{mg} / \mathrm{kg} /$ p.o. respectively, Group XV-XVII treated with total alkaloidal (TA) extract at the dose of 100, 200 and $300 \mathrm{mg} / \mathrm{kg} /$ p.o. respectively, Group XVIII treated with diclofenac $10 \mathrm{mg} / \mathrm{kg} / \mathrm{ml}$ as standard administered $1 \mathrm{~h}$ before the injection of carrageenan and this standard group study was once performed not repeated for root extracts. The volume of the paw was measured after $30 \mathrm{~min}, 1 \mathrm{~h}, 3 \mathrm{~h}$ and 6 hour of the injection of carrageenan. Edema was expressed as the increment in paw thickness due to carrageenan administration. Percent inhibition of edema volume between treated and control group were calculated.

\section{Results}

The human red blood cell (HRBC) membrane stabilization method

The results are reported in table 1 \& II. The chloroform, ethyl acetate, n-butanol, aqueous and total alkaloids extracts of stem and roots of Sesbania sesban were studied for in vitro anti-inflammatory activity by HRBC membrane stabilization method. The anti-inflammatory activity of the extracts was found on concentration dependent, with the increasing concentration, the activity is also increased. Among all the extracts in root and stem, n-butanol and aqueous extract at a concentration of $200 \mu \mathrm{g} / \mathrm{ml}$ showed maximum 70.37 and 68.89 percent protection respectively in HRBC stabilization in hypotonic solution. All the results were compared with standard Diclofenac which showed $72.29 \%$ protection. All extracts of root and stem were exhibited membrane stabilization effect by inhibiting hypotonicity induced lysis of erythrocyte membrane. Some of the NSAIDs are known to posses membrane stabilization properties which may contribute to the potency of their antiinflammatory effect. Though the exact mechanism of the membrane stabilization by the extract is not known yet; hypotonicity-induced hemolysis may arise from shrinkage of the cells due to osmotic loss of intracellular electrolyte and fluid components. The extract may inhibit the processes, which may stimulate or enhance the efflux of these intracellular components (Kumar et al., 2011). n-Butanol and aqueous extract showed significant in-vitro antiinflammatory activity in similar manner as standard.

Table 1: In-vitro anti-inflammatory activity of stem extracts of Sesbania sesban.

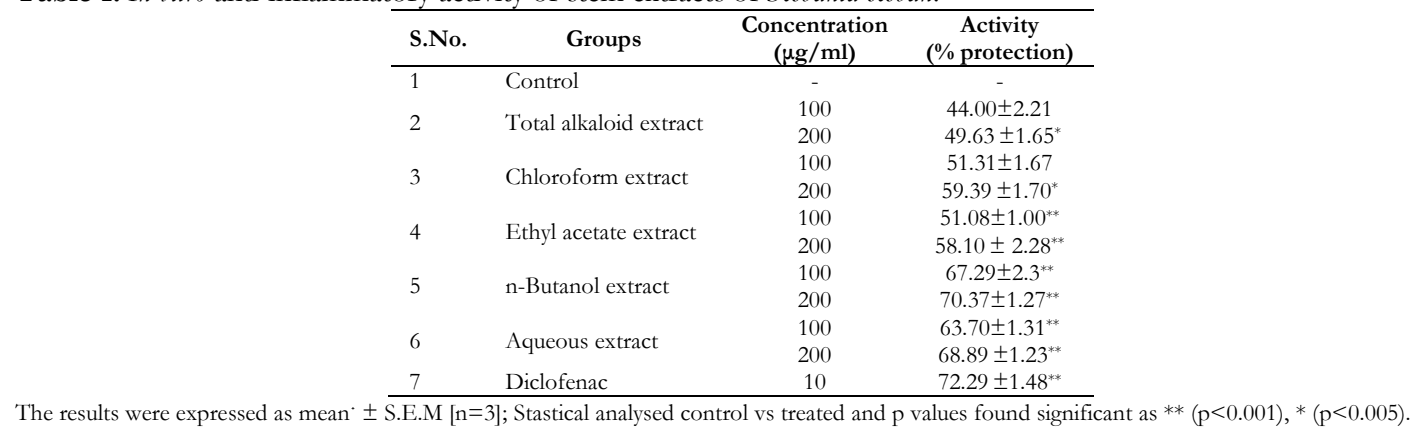


Table II. In-vitro anti-inflammatory activity of root extracts of Sesbania sesban

\begin{tabular}{clcc}
\hline S.No. & \multicolumn{1}{c}{ Groups } & $\begin{array}{c}\text { Concentration } \\
(\mathbf{m g} / \mathbf{m l})\end{array}$ & $\begin{array}{c}\text { Activity }(\% \text { Protection) } \\
\text { Mean } \pm \text { S.E.M [n=6] }\end{array}$ \\
\hline 1 & Control & - & - \\
2 & Total alkaloid extract & 100 & $34.12 \pm 0.22$ \\
& & 200 & $39.25 \pm 1.11^{*}$ \\
3 & Chloroform extract & 100 & $42.64 \pm 1.55^{*}$ \\
& & 200 & $53.78 \pm 1.02^{* *}$ \\
4 & Ethyl acetate extract & 100 & $51.84 \pm 1.33^{* *}$ \\
& & 200 & $56.00 \pm 1.35^{* *}$ \\
5 & n-Butanol extract & 100 & $61.32 \pm 1.56^{* *}$ \\
& & 200 & $68.6 \pm 2.44^{* *}$ \\
6 & Aqueous extract & 100 & $59.45 \pm 2.35^{*}$ \\
7 & Diclofenac & 200 & $61.66 \pm 1.87^{* *}$ \\
\hline
\end{tabular}

The results were expressed as mean \pm S.E.M* $[n=3]$.

Stastical analysed control vs treated and $\mathrm{p}$ values found significant as $* *(p<0.001), *(\mathrm{p}<0.005)$.

\section{In-vivo anti-inflammatory activity}

The chloroform, ethyl acetate, n-butanol, aqueous and total alkaloids extracts of stem and roots of Sesbania sesban at the dose level of 100,200 and 300 $\mathrm{mg} / \mathrm{kg}$ were studied for in-vivo anti-inflammatory activity using rat paw edema method. The maximum effect of root and stem extracts were observed with n-butanol and aqueous extracts. The results of after $6 \mathrm{hrs}$ are only reported in fig. 1 \& II and the effect found is very similar fashion as standard drug diclofenac. In all the groups the inhibition started decreasing after 3 hrs of the study continue till $6 \mathrm{hrs}$. The results of in-vitro studies also supported the invivo anti-inflammatory activity.

In-vivo anti-inflammatory activity of stem extracts of Sesbania sesban.

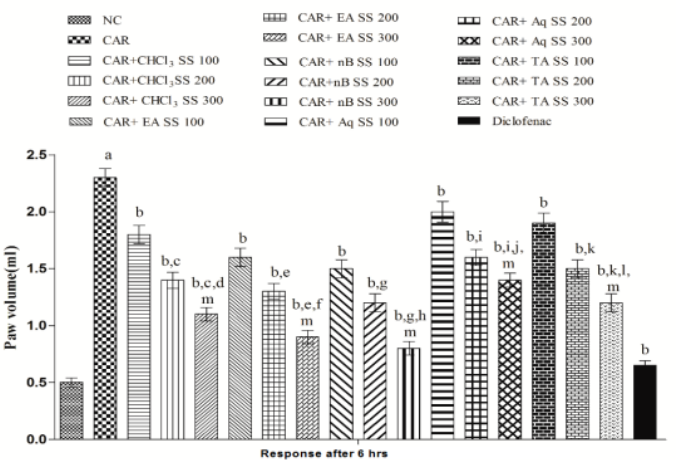

Fig.1. Effect of stem extract of Sesbania Sesban on paw edema in carrageenan treated rats.

The results were expressed as $[\mathrm{n}=6]$. The statistical analysis was carried out using one-way ANOVA followed by Dunnet test. ${ }^{*} \mathrm{P}<0.05$ a $P<0.001 \mathrm{v} / \mathrm{s}$ $\mathrm{NC},{ }^{\mathrm{b}} P<0.05 \mathrm{v} / \mathrm{s} C A R,{ }^{\mathrm{c}} P<0.01 \mathrm{v} / \mathrm{s} \mathrm{CHCl}_{3} \mathrm{SS}$ $100,{ }^{d} P<0.05 \mathrm{v} / \mathrm{s} \mathrm{CHCl}_{3}$ SS $200,{ }^{\text {e }} P<0.01 \mathrm{v} / \mathrm{s}$ EA SS $100,{ }^{\mathrm{f}} P<0.05 \mathrm{v} / \mathrm{s}$ EA SS $200,{ }^{\mathrm{g}} P<0.01 \mathrm{v} / \mathrm{s} \mathrm{nB}$ SS 100 h $P<0.05 \mathrm{v} / \mathrm{s} \mathrm{nB}$ SS $200,{ }^{\text {i }} P<0.01 \mathrm{v} / \mathrm{s} \mathrm{Aq}$ SS 100 i $P<0.05 \mathrm{v} / \mathrm{s}$ Aq SS $200 \mathrm{k} P<0.01 \mathrm{v} / \mathrm{s}$ TA SS $100{ }^{1} P<0.05 \mathrm{v} / \mathrm{s}$ TA SS 200 .

\section{In-vivo anti-inflammatory activity of root extracts of Sesbania sesban.}

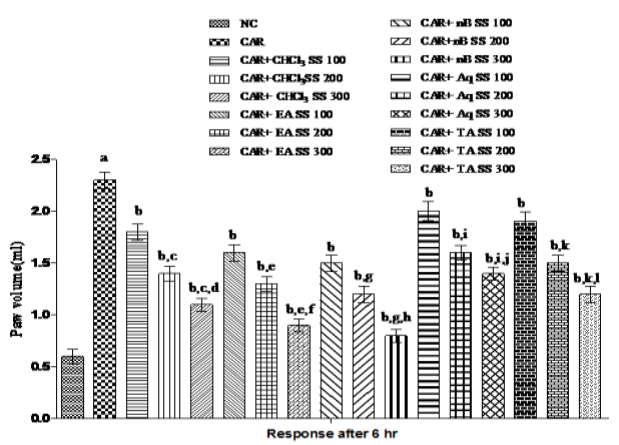

Fig.2. Effect of root extract of Sesbania Sesban on paw edema in carrageenan treated rats. The results were expressed as $[\mathrm{n}=6]$. The statistical analysis was carried out using one way ANOVA followed by Dunnet test. ${ }^{\mathrm{a}} P<0.001 \mathrm{v} / \mathrm{s} \mathrm{NC},{ }^{\mathrm{b}} P<0.05 \mathrm{v} / \mathrm{s} C A R$ c $P<0.01 \mathrm{v} / \mathrm{s} \mathrm{CHCl}_{3} \mathrm{SS} 100,{ }^{\mathrm{d}} P<0.05 \mathrm{v} / \mathrm{s} \mathrm{CHCl}_{3}$ SS $200,{ }^{\text {e }} P<0.01 \mathrm{v} / \mathrm{s}$ EA SS $100,{ }^{\mathrm{f}} P<0.05 \mathrm{v} / \mathrm{s}$ EA SS 200, g $P<0.01 \mathrm{v} / \mathrm{s} \mathrm{nB} \mathrm{SS} 100^{\mathrm{h}} P<0.05 \mathrm{v} / \mathrm{s} \mathrm{nB}$ SS $200,{ }^{\mathrm{i}} P<0.01 \mathrm{v} / \mathrm{s}$ Aq SS 100 i $P<0.05 \mathrm{v} / \mathrm{s} \mathrm{Aq}$ SS $200 \mathrm{k} P<0.01 \mathrm{v} / \mathrm{s}$ TA SS $100^{1} P<0.05 \mathrm{v} / \mathrm{s}$ TA SS 200

\section{Discussion and Conclusion}

Percentage inhibition of edema volume of all extracts of roots and stems of Sesbania sesban were calculated after every hour upto $6 \mathrm{~h}$ duration. There is dose dependent inhibition showed in paw edema in rats as shown in Fig. I \& II. Prostaglandins and bradykinins were suggested to play important role in carrageenan induced edema (Vinegar et al., 1969; Dray and Perkin, 1993). Previously studies suggested that, the steroidal and non-steroidal antiinflammatory drugs tested by the carrageenaninduced paw inflammation test. The $1 \%$ carrageenan induced edema in the rat paw is caused by inflammatory mediators like autocoids, histamine and 5-hydroxy tryptamine (5-HT) during the first phase within one hour, after which kinins act, to increase the vascular permeability upto two and a half hours. The maximum inflammation is seen approximately three hours post the carrageenan injection, after which it begins to decline. Following that the prostaglandins act from two and a half 
hours to six hours, which results in the migration of leucocytes into the inflamed site (Salomi et al., 1991). The carrageenan induced paw edema model in rats is known to be sensitive to cyclo-oxygenase (COX) inhibitors and has been used to evaluate the effect of non-steroidal anti-inflammatory agents. In-vitro anti-inflammatory studies of stems and root extracts of $S$. sesban were exhibited membrane stabilization effect by inhibiting hypotonicity induced lysis of erythrocyte membrane (Table 1 \& II). The erythrocyte membrane is analogues to the lysosomal membrane (Chou, 1997) and its stabilization implies that the extract may as well stabilize lysosomal membrane. Stabilization of lysosomal membrane is important in limiting the inflammatory response by preventing the release of lysosomal constituents of activated neutrophil such as bacterial enzymes and proteases which cause further tissue inflammation and damage (Murugasan, 1981). From the above study it was concluded that stems and root of $S$. sesban has significant anti-inflammatory potential as similar like standard drug diclofenac.

\section{Acknowledgements}

We would like to acknowledge that this research was carried out at Department of Pharmacology, ISF College of Pharmacy, Moga, Punjab (India) by providing the lab facility. We also thanks to IKG Punjab Technical University, Kapurthala for constant support for this study.

\section{References}

1. Kumar V, Bhat Z A, Kumar D, Bohra P, Sheela S. In-vitro anti-inflammatory activity of leaf extracts of Basella alba Linn. Int. J. Drug Dev. \& Res., April-June 2011, 3 (2), 176-179.

2. Kumar V, Bhat Z A, Kumar D, Khan N A, Chashoo IA. Evaluation of anti-inflammatory potential of leaf extracts of Skimmia anquetilia. Asian Pac I Trop Biomed. 2012, 2(8), 627-630.

3. Ramachandran S, Rajinikanth B, Rajasekaran A, Manisenthil KKT. Evaluations of anti-inflammatory and analgesic potential of methanol extract of Tectona grandis flowers. Asian Pac J Trop Biomed. 2011, S155-S158.

4. Sakat S, Juvekar AR, Gambhire MN. In vitro antioxidant and anti-inflammatory activity of methanol extract of Oxalis corniculata Linn. Int J Pharma \& Pharmacol Sci. 2010, 2 (1),146-155.
5. Kumar S, Bajwa BS, Kumar N. Evaluation of antibacterial activity of plant Sesbania sesban. International Journal of Pharmacy 2014, 4(1), 385396.

6. Vadivu R, Lakshmi K.S. In vitro and in vivo antiinflammatory activity of leaves of Symplocos cocbinchinensis (Lour) Moore ssp Laurina. Bangladesh J Pharmacol. 2008, 3, 121-124.

7. Gandhisan R, Thamaraichelvan A, Baburaj. Antiinflammatory action of Lannea coromandelica HRBC membrane stabilization. Fitoterapia 1991, 62, 82-83.

8. Chou CT. The anti-inflammatory effect of Tripterygium wilfordii Hook $\mathrm{F}$ on adjuvant-induced paw edema in rats and inflammatory mediators release. Phytother Res. 1997, 11, 152-54.

9. Isao $\mathrm{k}$ and Ikuyo KH. Flavonols from saffron flowers, tyrosinase activity and inhibition mechanism. J. Agric. Food Chem. 1999, 47, 4121-4125.

10. Morris CJ. Carrageenan-induced paw edema in the rat and mouse. Inflammation protocols. 2003,115-21.

11. AJ, Khadabadi SS, Farooqui IA, Bhutada VS. AntiInflammatory activity of leaves of Argyreia nervosa in carrageenan-induced paw edema in rats. Pharmacognosy Journal. 2010, 2(8), 229-32.

12. Gandhisan R, Thamaraichelvan A, Baburaj. Antiinflammatory action of Lannea coromandelica HRBC membrane stabilization. Fitoterapia 1991, 62, 82-83.

13. Vinegar R, Scheriber M, Hugo R. Biophasic development of carrageenan odema on rats, J Pharmacol Exp Ther. 1969, 166, 96-103.

14. Dray A, Perkin M. Bradykinin and inflammatory pain, Trends Neurosci. 1993, 16, 99-104.

15. Murugasan N, Vember S, Damodharan C. Studies on erythrocyte membrane IV. In vitro haemolytic activity of Oleander extract. Toxicol Lett.1981, 8; 33 38.

\section{Cite this article as:}

Baljinder Singh, Rajiv Sharma, A.N. Kalia. Antiinflammatory potential of root and stem extracts of Sesbania sesban. Annals of Plant Sciences 6.11 (2017) pp. 1790-1793.

doi: http://dx.doi.org/10.21746/aps.2017.6.11.12 